\title{
Detecting spatio-temporal changes of arable land and construction land in the Beijing-Tianjin corridor during 2000-2015
}

\author{
GUO Liying ${ }^{1,2},{ }^{*}$ DI Liping ${ }^{2}$, TIAN Qing ${ }^{3}$
}

1. Institute of Agricultural Resources and Regional Planning, Chinese Academy of Agricultural Sciences, Beijing 100081, China;

2. Center for Spatial Information Science and Systems, George Mason University, Fairfax, VA 22030, USA;

3. Department of Computational and Data Sciences, George Mason University, Fairfax, VA 22030, USA

\begin{abstract}
Rapid peri-urbanization has become a new challenge for sustainable urban-rural development worldwide. To clarify how unprecedented urban sprawl at the metropolitan fringe impacts urban-rural landscape, this study took the Beijing-Tianjin corridor of Beijing-Tianjin-Hebei metropolitan area, one of the largest urban clusters in China, as a typical example. By using Landsat-based landscape metrics and a practical methodology, we investigated the landscape changes and discussed the potential reasons in the context of rapid peri-urbanization of China. Specifically, multi-temporal land use maps derived from Landsat images were used to calculate landscape metrics and analyze their characteristics along the urban-rural gradients. The practical methodology was used to monitor spatio-temporal characteristics of landscape change in large metropolitan areas. The results showed that landscape patterns in the area had changed greatly from 2000 to 2015 with characteristics of construction land sprawl and arable land shrinkage. The intensity and scale of landscape changes varied along the urban-rural gradients. Sampled plots in urbanized areas and rural areas demonstrated distinguishable landscape patterns and significant differences. Urban areas had more heterogeneous and fragmented landscapes than rural areas. Peri-urban areas in general experienced higher levels of land diversification than rural areas. Rural residential land appeared to be more aggregated near Beijing and Tianjin cities. Besides, our findings also indicated that urban expansion was largely responsible for landscape patterns. The findings of this study potentially provide strategical insights into landscape planning around mega cities and sustainable coordinated urban-rural development.
\end{abstract}

Keywords: spatio-temporal characteristics; arable land; construction land; peri-urbanization; Beijing-Tianjin corridor (BTC); metropolitan area; China

Received: 2018-07-20 Accepted: 2018-12-19

Foundation: National Key Research and Development Program of China, No.2017YFC0504701

Author: Guo Liying, $\mathrm{PhD}$ and Associate Professor, specialized in land use and agricultural development. E-mail:1guo2@gmu.edu

"Corresponding author: Di Liping, PhD and Professor, E-mail: 1di@gmu.edu 


\section{Introduction}

With the rapidly increasing peri-urbanization, landscape changes at the urban fringe for the urban renewal and urban sprawl have become a new challenge for sustainable urban-rural development (Nilsson et al., 2014; Liu et al., 2018a). Uncontrolled and unplanned urban sprawl has created the imbalance between excessive consumption of resources and regional development, especially in megacities of developing countries under the pressure of population increase and clime change (Zhao, 2010; Qian et al., 2016). Urban sprawl of large urban areas into the surrounding rural landscape leads to the rapid expansion of urban land along with the sharp shrink of rural land (Li et al., 2014). China is a typical country undergoing fast urbanization and land-use change. In the past two decades, on average more than 2000 square kilometers of rural land was requisitioned for urban sprawl per year (Forbes, 2016 https:/www.forbes.com/sites/wadeshepard/2016/03/14/the-impact-of-chinas-new-urbanizati on-plan-could-be-huge/\#28a6315d6673). Therefore, in the context of rapid urbanization, how to effectively utilize limited land resources to achieve sustainable development at the urban-rural fringe is a key issue for land science community. Also, to clarify this issue will be helpful for attaining a balance among urban development, economic growth and social well-being (Simwanda and Murayama, 2018).

Urbanization plays a crucial role in promoting economic development and solve the dual structure of urban and rural areas for China (Liu et al., 2013; Li et al., 2018). During the period of 1990-2015, the total rural population decreased from 841.38 million to 603.46 million, while the urban population increased from 301.95 million to 771.16 million (NBSC, $2016 \mathrm{http}: /$ www.stats.gov.cn/english/Statisticaldata). The share of urban population changed from $17.91 \%$ in 1978 to $56.1 \%$ in 2015 (NBSC, 2016). Rapid urbanization and growth of urban economy have led to unprecedented activities in urban construction and urban sprawl in space (Gao et al., 2016). A significant loss of cropland in China has been reported as a direct consequence of urban expansion. With continued economic development and urban growth, the demand for construction land will continue to increase.

Landscape changes reflect the changes in landscape structure, function, and spatial pattern over time (Antrop, 2004). Such changes result from the interaction between natural environments and human activities (Liu et al., 2013). As urbanization develops fast across developing countries, understanding how urban economic development affects landscape changes in urban areas has become an important focus of land science community (Long et al., 2009; Li et al., 2014).

Urban expansion has great influences on landscape patterns, especially in urban fringes. Bittner and Sofer (2013) observed three different urban-rural fringe belts along the coastal area in Israel, and further reported that the continued expansion of built-up areas had been occurring in the urban-rural fringe. Roose et al. (2013) found that the patchy and scattered land in the urban fringe was formed by occupying agricultural land, grasslands and forests. In China, urban expansion has triggered a series of problems in the surrounding areas around metropolises, such as arable land reduction and resources shortage, creating complex relationships between urban and rural areas (Li et al., 2015; Liu et al., 2017). From the late 1980 s to 2010 in China, approximately $3.18 \times 10^{6}$ ha of arable land were converted into construction land with about $50.68 \%$ of decreased arable land used for urban construction (Liu 
et al., 2014). Loss of millions of hectares of arable land to sprawl for urban construction needs has highlighted the conflict between urbanization and arable land conservation. Problems such as rural hollowing and idle rural homesteads have emerged in the countryside due to migration of population from rural to urban areas (Song et al., 2013; Long, 2014; Liu and $\mathrm{Li}, 2017)$. To protect arable land for feeding huge population, a series of strict land-use management policies were introduced, including "arable land requisition-compensation balance policy", and "land consolidation and rehabilitation" (Long et al., 2010; Liu et al., 2014). The competition for different uses of land is particularly acute amid limited supply of land.

The metropolitan area is an area of rapid expansion of construction land and prominent human-land conflict. Existing research on land use in metropolitan areas has mainly focused on changes in urban areas (Seto and Fragkias, 2005). Some studies examine landscape patterns in metropolitan areas in terms of spatial heterogeneity and temporal heterogeneity (Lechner et al., 2013; Lv et al., 2012; Nagendra et al., 2004; Poelmans and Van Rompaey, 2009). Giving a brief summary of their findings, Kowea et al. (2015) argued that landscape metrics were useful tools to describe the composition and configuration of landscape change in the Sancaktepe District of Istanbul Metropolis, attributable to agglomerated and fragmented land-use patches caused by urban expansion. Dewan et al. (2012) determined the impact of land-use change on landscape fragmentation with landscape metrics in Dhaka Metropolis of Bangladesh, finding that the landscape became highly fragmented due to rapid increased built-up areas. Aguilera et al. (2011) simulated the scenarios in a Spanish metropolitan area and evaluated quantitatively their changes in the spatial characteristics of urban growth with landscape metrics. They found more dispersed growth patterns in metropolitan areas. Li et al. (2012) measured spatial pattern of greenspace in Beijing metropolitan area with seven landscape metrics, suggesting that land surface temperatures were positively correlated with patch density.

More detailed studies of landscape changes are needed to understand the spatial and functional changes along the urban-rural gradients around metropolises. These understandings are of great importance for landscape planning and resolving the multiple issues associated with urban expansion (Liu et al., 2016; Tian et al., 2016). Urban expansion is inevitable in the process of socio-economic development, and how to manage land at the urban-rural interface will remain a challenge for China in the present and future. As China has just launched an ambitious plan for developing city clusters at unprecedented scales (Lu, 2015), it becomes even more important to understand what is happening and will likely happen around these urban clusters.

This study, taking the Beijing-Tianjin corridor (BTC) in Beijing-Tianjin-Hebei metropolitan region as the study area, aims to examine the impacts of urbanization on landscape patterns. Particular attention is paid to the spatio-temporal and functional changes along the urban-rural gradients. The findings of this study will potentially provide policymakers with a sound scientific basis for urban planning and land use management. Besides, the study area is one of the typical core city clusters in the newly announced Chinese urban development plan. The understandings gained from this study will have implications for regional planning and for other metropolitan areas. 


\section{Materials and methods}

\subsection{Study area}

This study focuses on the Beijing-Tianjin corridor (BTC) within the Beijing-Tianjin-Hebei (also termed as Jing-Jin-Ji) metropolitan region (Figure 1), which includes two municipal cities, Beijing and Tianjin, and their neighboring areas in Hebei province. BTC covers an area of $4509 \mathrm{~km}^{2}$, including Daxing and Tongzhou districts of Beijing, Wuqing district of Tianjin, and Langfang municipal district under the jurisdiction of Hebei province. Beijing and Tianjin, as the first-tier Chinese cities, suffer many common big city problems, such as employment pressure, traffic congestion, air pollution, and soaring housing and living cost (Gu et al., 2015). To address those problems, new urban centers have been increasingly developed, which often take over arable land at the peri-urban areas and inevitably lead to the spread of built-up area from the original urban centers to the surrounding areas (Wang \& Wang, 2015). All these raise important questions related to urbanization in BTC, such as what are the patterns and trends of urban development in BTC? And what changes have occurred on the landscape as a consequence of urban expansion?

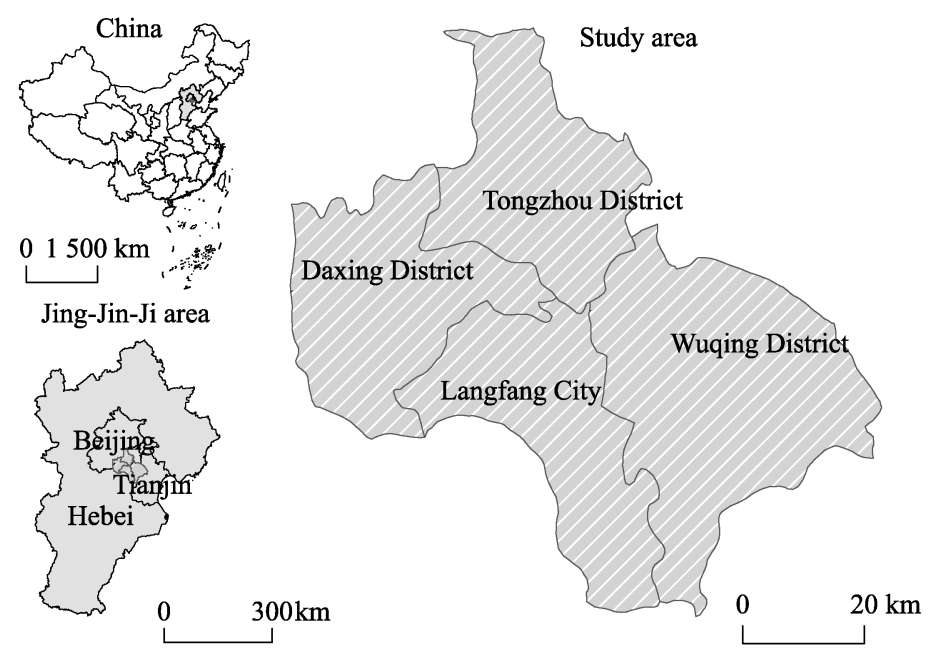

Figure 1 The location of the Beijing-Tianjin corridor within the Beijing-Tianjin-Hebei metropolitan area

\subsection{Data and statistical analyses}

\subsubsection{Data}

Our study relies on a gridded land-use dataset in years of 2000, 2005, 2010 and 2015 at a scale of 1:100,000 with a spatial resolution of $30 \mathrm{~m}$, provided by the Data Center for Resources and Environmental Sciences, Chinese Academy of Sciences (RESDC). The land-use dataset was generated originally by visual interpretation of Landsat TM/ETM+, OLI and HJ-1 sensors (Liu et al., 2014; Liu et al., 2018b). Other spatial data, including digital elevation model (DEM), county boundary and road networks, were also used to support image interpretation. The overall accuracy of land use data computed by the confusion matrix was over $90 \%$ with kappa coefficients being greater than 0.8 (Liu et al., 2014). 
In this study, the original land-use types were reclassified into four main types: urban built-up land (UBL, the built-up area of large, medium and small cities and towns), rural residential land (RRL, rural residential areas outside cities and towns), arable land (ARL, land for growing crops), and other construction land (OCL, factories and mines, large industrial parks, transportation, airports, etc). The first three types all belong to the general construction land types. To analyze the spreading effects of urban centers across BTC, the built-up areas of Beijing and Tianjin in 2000, 2005, 2010, and 2015 were also extracted. All the spatial processing was conducted with the help of ArcGIS software.

\subsubsection{Landscape metrics}

Landscape indices are often used to quantitatively characterize landscape patterns (Fernandes et al., 2011). Specifically, class-level indices calculated for each land-use type can reveal landscape patterns of individual land-use types. Analyzing class-level indices can help us understand the change in land-use type individually and reveal the mechanism of farmland conversion. Following the existing researches, three common indices, i.e., percentage of landscape (PLAND), edge density(ED) and aggregation index (AI) are used in this study (Shoyama and Braimoh, 2011). PLAND characterizes landscape composition. AI reflects the aggregation/dispersion of the same-type patches. ED indicates the degree of fragmentation of patches. In addition, two landscape-level indices, Shannon's diversity index (SHDI), and Contagion index (CONTAG), were also used to evaluate temporal changes of landscape due to urbanization in BTC. Contagion index is inversely related to edge density affected by both the dispersion and interspersion of patch types (McGarigal et al., 2009). These landscape-level indices analyze the changes in all land-use types within a specific region (Fan and Myint, 2014).

(1) Rate of land change

The rate of land-use change reflects the speed of change for a certain land-use category at a time period (Guo et al., 2015). The formula is as follows:

$$
P_{i j}=\frac{L_{j}-L_{i}}{L_{i}} \times 100 \%
$$

where $P_{i j}$ is the rate of land-use change for a specific landscape category at a specific time period, and $L_{i}$ and $L_{j}$ are the area of a certain land-use category at the beginning and end of a specific time period T.

$$
A_{i j}=\frac{\mathrm{L}_{j}-\mathrm{L}_{i}}{\mathrm{~L}_{i}} \times \frac{1}{T} \times 100 \%
$$

Equation (2) is the rate of landscape changes at the unit time of $T$ for a specific land-use category. If the unit of $\mathrm{T}$ is year, $A_{i j}$ is the annual rate of change.

(2) Land-use transition matrix

Transition matrix is a traditional method to quantitatively estimate landscape changes during a time period (Han and Liu, 2013). Transition matrix was calculated by using overlay function in ArcGIS 10.2 and analyzed for land-use transition among land-use categories in Excel. The rate of loss and gain are two indices used to quantitatively estimate the situation of landscape changes from the beginning to the end of a period. The loss rate is defined as: 


$$
L_{i j}=\frac{T_{i j}}{\sum_{i=1}^{n} L_{i}} \times 100 \%
$$

where $\sum_{i=1}^{n} L_{i}$ is the total area of land-use categories at the beginning time $i$, and $T_{i j}$ is the transition area of a certain land-use category from time $i$ to time $j$.

The gain rate is defined as:

$$
G_{i j}=\frac{T_{i j}}{\sum_{j=1}^{n} L_{j}} \times 100 \%
$$

where $\sum_{j=1}^{n} L_{j}$ is the total area of land categories at the end time $j$.

Other indices such as rates of total loss and total gain, and net change rate are used to analyze the characteristics of landscape changes. The formulas are as follows:

$$
\begin{gathered}
T L_{i j}=\frac{\sum_{i}^{n-1} T_{i j}}{\sum_{i=1}^{n} L_{i}} \times 100 \% \\
T G_{i j}=\frac{\sum_{j}^{n-1} T_{i j}}{\sum_{j=1}^{n} L_{j}} \times 100 \% \\
C_{i j}=\frac{\sum_{j=1}^{n} L_{j}-\sum_{i=1}^{n} L_{i}}{\sum L} \times 100 \%
\end{gathered}
$$

Equation (5) is the total loss rate of a specific land-use category from the beginning time $i$ to the end time $j$, and $\sum_{i}^{n-1} T_{i j}$ is the total area of rollout from a specific land-use category to other land-use categories from time $i$ to time $j$. Equation (6) is the total gain rate of a specific land-use category from the beginning time $i$ to the end time $j . C_{i j}$ is the net change rate of a specific land-use category from the beginning time $i$ to the end time $j$, and $\sum L$ is the total area of all land-use categories.

The landscape indicators discussed above were calculated by using Fragstats 4.2 that is an open-source software program designed to compute various landscape metrics.

\section{Results}

\subsection{Land-use changes}

During the period of 2000-2015, construction land categories overall experienced a rapid expansion in BTC (Table 1). Of which, the category of urban construction land showed the most significant expansion with an increase of $100.43 \%$ and the category of other construction land also experienced a rapid expansion with a total increase of $90.51 \%$. While the fastest growth period of urban built-up land was 2000-2005 with a total increase of $72.12 \%$, the 
fastest growth period of other construction land occurred later in the study period from 2010 to 2015 with an increase of $46.19 \%$. These results indicated that urban construction and infrastructure development made a remarkable change on the land use in BTC over the past 15 years. Rural residential land also experienced sizable expansion (12.54\%) but was much less significance than the land-use categories of urban built-up land and other construction land. On the contrary, arable land experienced continuous loss from $76.23 \%$ in 2000 to $69.76 \%$ in 2015 (Table 1).

Table 1 Land-use changes in the Beijing-Tianjin corridor during 2000-2015 (\%)

\begin{tabular}{|c|c|c|c|c|c|c|c|c|}
\hline \multirow{2}{*}{ Landscape } & \multicolumn{2}{|c|}{$2000-2005$} & \multicolumn{2}{|c|}{$2005-2010$} & \multicolumn{2}{|c|}{ 2010-2015 } & \multicolumn{2}{|c|}{$2000-2015$} \\
\hline & Periodic & Annual & Periodic & Annual & Periodic & Annual & Periodic & Annual \\
\hline Arable land & -6.86 & -1.37 & 0.50 & 0.10 & -2.24 & -0.45 & -8.49 & -0.57 \\
\hline Urban built-up land & 72.12 & 14.42 & 10.41 & 2.08 & 5.46 & 1.09 & 100.43 & 6.70 \\
\hline Rural residential land & 14.06 & 2.81 & -4.09 & -0.82 & 2.88 & 0.58 & 12.54 & 0.84 \\
\hline Other construction land & 6.54 & 1.31 & 22.32 & 4.46 & 46.19 & 9.24 & 90.51 & 6.03 \\
\hline
\end{tabular}

The expansion of construction land was mostly due to conversion of arable land. The total area of land converted from arable land to construction land was 28,688 ha, accounting for $9.14 \%$ of arable land area in 2000. The largest conversion from arable land to construction land (28,091 ha) occurred in the period of 2000-2005, which was about $8.95 \%$ of the area of arable land in 2000. The total decrease in arable land $(29,168$ ha) from 2000 to 2015 was approximately equal to the increase in construction land $(30,869 \mathrm{ha})$.

Land-use changes in BTC also showed interesting spatial patterns (Figure 2). There is a common pattern in urban expansion for the study area: expansion firstly focuses in city center and then agglomerates along city fringe. Arable land is still the dominant type in BTC. The landscape of BTC represents a typical area of urban-suburban-rural gradients.

The built-up land in Beijing is expanding southeastward and mainly concentrated in three directions: along BTC and in the boundary areas of Tongzhou district and Daxing district. In the document of Outline of the 12th Five-year Plan for Economic and Social Development in Tongzhou District issued by the Beijing Tongzhou District People's Government in 2011, Tongzhou was planned to be Beijing's new secondary Central Business District. Tianjin's built-up area expanded both northwestward and southeastward. This may due to the fact that Tianjin, located north-west to the Bohai Bay, is the largest costal city in northern China and its expansion of urban built-up land to the southeast may be related to port construction and development of near-port industrial parks. Meanwhile, as the two core cities of Jing-Jin-Ji metropolitan area, the connections in the transportation and other systems between Tianjin and Beijing seemed to push Tianjin's expansion also toward northwest. However, only one new urban center appeared in Wuqing District close to the boundary of Tianjin built-up area. The main growth of Tianjin city occurred southeastward the bay area. Compared to Beijing, the intensity and scope of Tianjin's urban expansion along BTC seemed significantly weaker. Beijing seemed to have more influences on its surrounding areas than Tianjin, especially in BTC, and contributed more to the growth of construction land in BTC. 

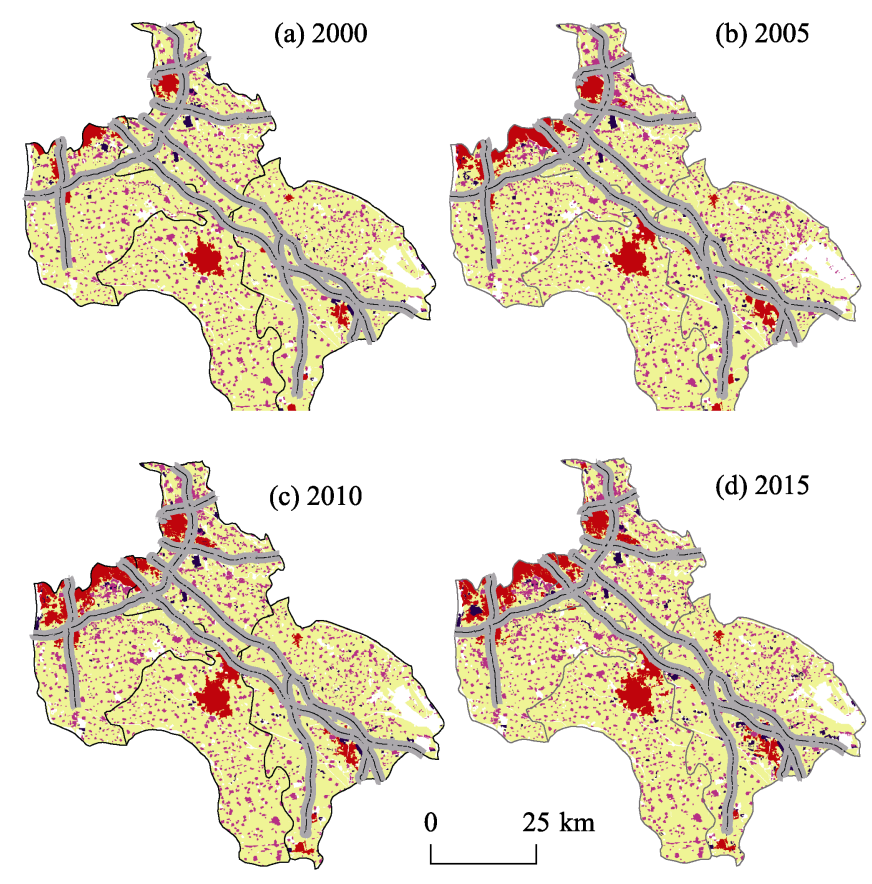

$$
\begin{array}{ll}
\square \text { Arable land } & \text { Rural residential land } \\
\square \text { Urban built-up land } & \text { Other construction land } \\
& =\text { Highway }
\end{array}
$$

Figure 2 Land-use changes in the Beijing-Tianjin corridor during 2000-2015

Langfang city, located in the middle of BTC, has become an important junction of Beijing, Tianjin and Hebei's urban agglomeration along with the development of Jing-Jin-Ji metropolitan areas. The urban expansion in Langfang city was different from that of Beijing and Tianjin. Leaping expansion can be characterized with far away from old city center and close to the Jing-Jin express highway. The new city center is $10 \mathrm{~km}$ apart from the fringe of the old city (Figure 2).

\subsection{Landscape characteristics along urban-rural gradients}

To further understand urban-rural linkages and assess the spreading effects of urban centers on landscape changes, the Beijing-Tianjin corridor was divided into five zones labeled as N1, N2, C, S2, and S1 (Figure 3). The five zones are approximately $15 \mathrm{~km}$ wide each and span the area of urban-rural continuum in BTC from urban area to rural area, urban area again, and then rural area again. N1's south boundary was set first by $5 \mathrm{~km}$ southeastward from Beijing's Sixth Ring Road. N2, C, and S2 were then identified by using a 15-km buffer along the Beijing-Tianjin corridor. The class-level and landscape-level landscape indices were calculated for each zone separately (Figures 4 and 5).

The landscape-level indices showed several patterns along BTC (Figure 4). There was an increase in diversity and a decrease in contagion over time, particularly in N1 (near Beijing), C (near Langfang), and S1 (near Tianjin), suggesting the influence from urban development over peri-urban areas. However, N1 showed significant differences from other zones, with 
the greatest increase in patches, the greatest SHDI, lowest CONTAG, indicating Beijing's influence for its immediate surrounding areas.

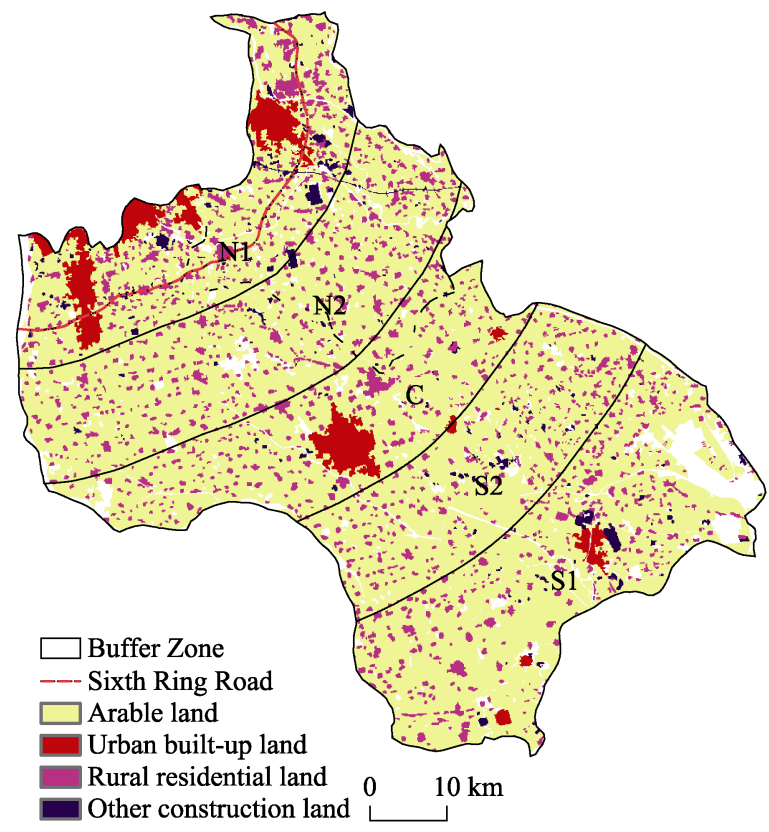

Figure 3 Urban-rural gradient zoning based on the land use map of the Beijing-Tianjin corridor in 2000
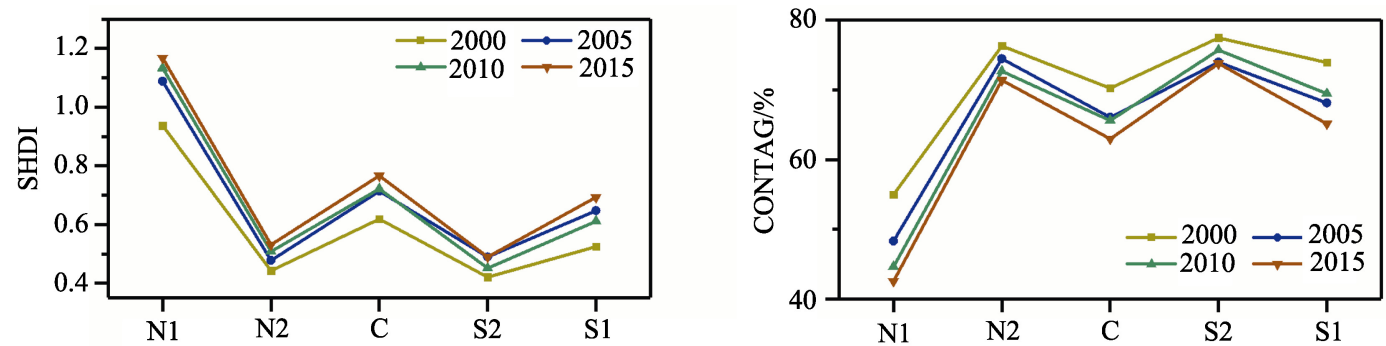

Figure 4 Landscape-level indices along the Beijing-Tianjin corridor during 2000-2015. SHDI and CONTAG represent Shannon's diversity index and Contagion index, respectively.

The class-level indices provide further insights about landscape patterns and their changes in the study area (Figure 5). The PLAND index for arable land decreased most significantly in N1, again indicating Beijing's influence (Figure 5a). Percentage of arable land also decreased in $\mathrm{C}$ and $\mathrm{S} 1$ but to a limited extent. In N2 and S2 (areas between but not near cities), there was little change in percentage of arable land, which remained the dominant land use type. The PLAND index for urban built-up land showed opposite patterns from those for arable land, with a relatively large increase in $\mathrm{C}$, which was consistent with the process of formation and growth of new urban areas in Langfang.

Interestingly, N1 also witnessed the largest increase in rural residential land (Figure 5a). While each zone experienced increases in other construction land, the largest increase was in 

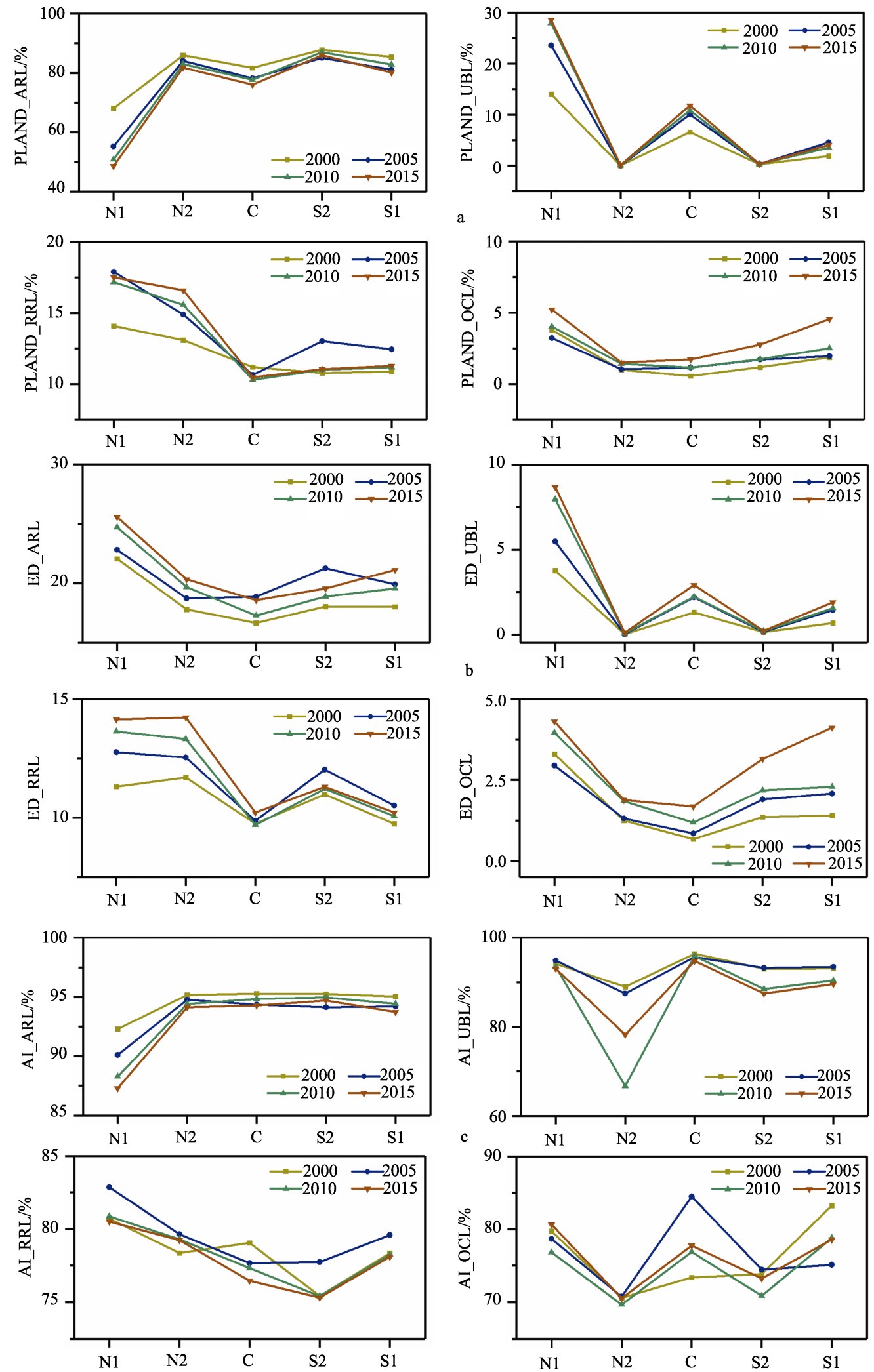

Figure 5 Class-level indices along the Beijing-Tianjin corridor during 2000-2015 
S1, indicating Tianjin's influence was associated with its important industrial position and port trades. Metropolises seemed to have a certain impact on their immediate surrounding areas: Beijing's influence on rural residential land might have reached N2, and Tianjin's influence over other construction land might have reached S2 and C.

The edge density index increased for all land-use types over time in BTC (Figure 5b). The most striking change in the number of patches was found to be arable land in N1. Considering that $\mathrm{N} 1$ also experienced the greatest decline in percentage of arable land, this suggests Beijing's influence over farmland conversion and fragmentation as well in its immediate surrounding areas. ED increased for urban built-up land in N1, C and S1, again indicating the influence from urban development over peri-urban areas. But the most worth noting is S1: if we consider that the percentage of urban built-up land in S1 changed very little, this suggests further dividing of urban built-up land in S1. Other ED, particularly for other construction land, are in general compatible with PLAND patterns, suggesting their changes in amount are consistent with changes in the value of ED.

By checking the aggregation index, AI, for N1 again, it showed significant differences from other zones with the lowest AI for arable land, suggesting dispersion of farmland (Figure $5 \mathrm{c}$ ). N1 and S1 showed relatively high AI for rural residential land compared to other zones, suggesting rural housing was more aggregated near Beijing and Tianjin. In zone C, AI for other construction land first decreased and then increased, and this, again, probably reflects the process of new development and gradual growth in the peri-urban areas of Langfang (Figure 5c). Notice that urban built-up land also increased in zone $\mathrm{C}$ but AI for urban built-up land remained the same. This suggests that unlike the category of other construction land that probably started in different areas and increased the agglomeration over time, urban built-up land probably grew through fringe expansion. In N2, AI increased for urban built-up land from 2010 to 2015 following decreases in earlier periods, and this may suggest growth of towns in rural areas resulting from the development policy (Long and Liu, 2016).

Overall, the five zones along BTC appeared to have distinct characteristics. Zone N1 can be characterized as dramatic changes in multiple aspects: reduction, fragmentation and dispersion of arable land, increase in all types of construction land, including rural residential land, as well as increase in land-use diversity. All these likely reflect Beijing's strong influence and are associated with development advantages near Beijing. The defining characteristics for $\mathrm{S} 1$ are expansion of other construction land and further division of urban built-up land, indicating Tianjin's influence and possibly related to Tianjin's important industrial position and port trades. Urban expansion was the key feature of Zone C, likely reflecting the process of new development and growth in the Langfang District and spurred by the Beijing-Tianjin urban cluster. N2 and S2, located between but not near cities, remained rural with relatively little changes, except for some increase in rural residential areas over time.

Additionally, peri-urban areas in general experienced higher levels of land-use diversification than rural areas. Rural residential land appeared to be more aggregated near Beijing and Tianjin. Beijing's influence over rural residential land and Tianjin's influence over other construction land might have reached beyond their immediate surrounding areas. 


\section{Discussion}

\subsection{Landscape changes under administrative hierarchy}

In this study, we found that spatial agglomeration, particularly in peri-urban areas, was a major characteristic for all types of construction land, including rural residential land, but the agglomeration intensity and pattern varied across the five zones. All these likely reflected Beijing's influence on BTC was stronger than Tianjing's and Langfang's. Spatial agglomeration was generally shaped or affected by various factors, including socio-economic contexts (Liu et al., 2015b), geographical location (Wei, 2015), as well as the central and local governmental policies (Yu and Wei, 2008), which could eventually lead to regionally divergent growth. Regional divergence is also sensitive to administrative ranks, such as Beijing as the capital of China, which is more likely to obtain resources and stronger supports from the central government for urban expansion and economic development due to its political advantages (Yu and Wei, 2008). This could also explain why spatial agglomeration for built-up land in urban fringe of Beijing was stranger than those of Tianjin and Langfang. However, as shown in Table 2, cities with higher administrative rank might not have a higher rate of urban expansion. The administrative rank of cities in BTC was Beijing $>$ Tianjin $>$ Langfang, but the urban expansion rates did not follow this rank. In fact, urban expansion rate of Langfang was the highest among the cities in the study area. This finding seemed in agreement with the finding of some studies that the urban expansion rate was negatively related to city size (Sun and Zhao, 2018), but not in agreement with finding of other studies that cites with higher administrative ranks had higher rate of urban expansion (Li et al., 2015; Zhao et al., 2015). The document, entitled Planning Outlines for Integrated and Coordinated Development of Beijing, Tianjin, and Hebei released by the central government of China in 2015, promoted the coordinated development and urbanization of Jing-Jin-Ji metropolitan area, as evidenced by the fastest urbanization in Langfang among the cities in BTC. Thus, urban expansion in BTC was associated with administrative hierarchy by building favorable socio-economic and policy contexts. It was also limited by current national development strategy: "strictly control the growth of large cities, rationally develop medium sized cities, and vigorously promote the development of small cities and town" (Li, 2012). How to deal with the relationship between urban expansion and national or regional development strategies and how to optimize urban-rural spatial structure in the context of administrative hierarchy had been the challenges for development planners in China. The above analysis provided a clue for meeting the challenges.

Table 2 Land urbanization rates along the Beijing-Tianjin corridor (\%)

\begin{tabular}{|c|c|c|c|c|c|}
\hline & N1 & $\mathrm{N} 2$ & $\mathrm{C}$ & S2 & $\mathrm{S} 1$ \\
\hline 2000 & 43.90 & 0.045 & 35.87 & 1.88 & 12.70 \\
\hline 2005 & 52.83 & 0.047 & 45.94 & 1.82 & 23.96 \\
\hline 2010 & 56.87 & 0.237 & 48.58 & 2.12 & 20.29 \\
\hline 2015 & 55.73 & 0.484 & 49.13 & 1.97 & 20.16 \\
\hline
\end{tabular}

\subsection{Landscape changes under policy context}

At the past 15 years, as shown in Figure 6, BTC's urban expansion experienced a process 


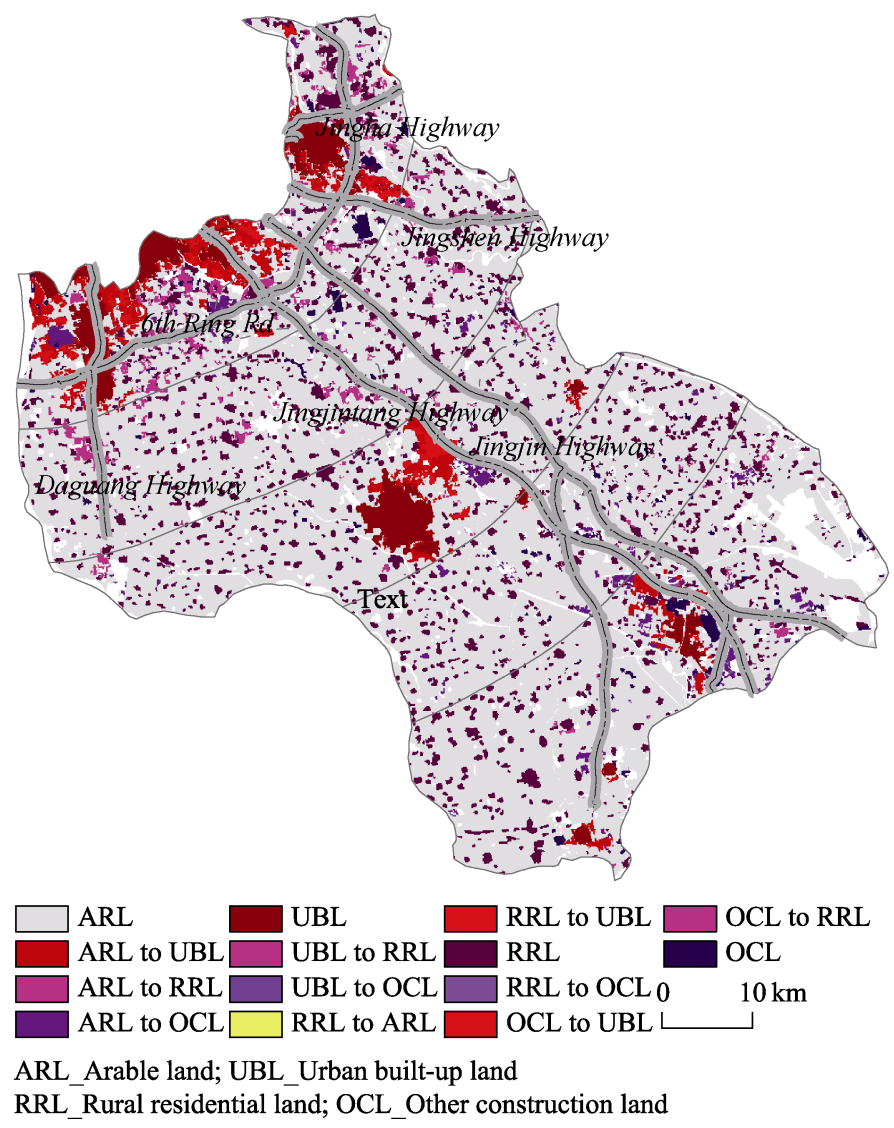

Figure 6 Landscape changes in the Beijing-Tianjin corridor during 2000-2015

from diffusion to aggregation, similar to the process described in the study of Dietzel et al. (2005). As a matured metropolis, Beijing's urban expansion might adopt a new diffusion process. The analysis showed that rapid zones of urban growth in Beijing were mainly around multiple sub-centers in N1. These new concentrations of urban development formed sub-centers of Beijing, with aggregation of high-tech industrial parks and special economic zones promoted by the General Development Plan of Beijing during the period of 2004-2020. According to the general plan, Tongzhou was designated as the administrative sub-center Beijing, whereas Daxing would be the center of modern manufacturing. These policies greatly affected the characteristics of urban expansion in those sub-administrative regions of Beijing. The general land use plan during the period of 2006-2020 for Wuqing District of Tianjin proposed the built-up land with the spatial patterns along "one new city, seven industrial parks, and three central towns." The spatial characteristics and patterns of the land use, as the outcome of such planning and policy guidelines, were diffusion and coalescence in landscape structure. The sub-center of Langfang was built close to Jing-Jin-Tang express highway in isolation far away from the old city. The coordinated development between the main city and its sub-centers was suggested in the General Land Use Plan of Langfang during the period of 2006-2020. Therefore, there was a clear variation among N1, $\mathrm{S} 1$ and $\mathrm{C}$ in the patterns of urban expansion due to the differences in urbanization stage, 
tion stage, policy, and available land. Under the stimulation of collaborative development policies, the most portion of increased construction land was used for building inner-city and inter-city highways and residential housing. Therefore, urban expansion is a complex system interwoven with socio-economic, political, and physical context, and thus any change in landscape patterns should be accompanied by a collaborative planning to ensure that the system's complexity is well-understood and well-controlled.

\subsection{Policy implications on urban-rural development}

The area concerned in this study is on urban-rural gradients. The rapid urbanization in the 15-year study period has significantly changed the landscape of the study area. Since landscape is a mirror reflecting the reality of urbanization and socio-economic development, the temporal changes of landscape can describe and reveal the progress and health of urbanization and socio-economic development, especially in its structure, function, effectiveness, and sustainability (Yang et al., 2017)

Clarifying issues associated with rapid urbanization and socio-economic development is of great theoretical and practical value (Li et al., 2018). Urbanization is not to simply expand its scale, but to highlight its corresponding issues, such as environment, infrastructure, traffic, culture, and migrant workers. This study reveals that urbanization should not only expand the size of the urban area, like BTC in the early 2000s, but also pay more attention to strengthening ecological construction, optimizing land-use structure, increasing the proportion of ecological land use, and promoting the level of urban livability, like BTC in the 2010s. Landscape changes in rapid urbanization areas also reveal evolution of internal functions of urban systems, such as industrial structure and economic, societal, and ecological functions of land use. Moreover, study on land-use process and structure can help model future land-use scenarios, which is beneficial to make the optimal urbanization strategy. Focusing on further optimizing the urban and industrial systems, the construction of central cities, key towns, and new communities will be on the priority, as well as low-carbon, environmentally-friendly strategic new-type industrial lands, and the important role of land allocation in regional transformation and industrial upgrading will be brought into play.

An urbanizing region may be across multiple municipalities, like the BTC case in this study. The planning and their related polices of individual municipalities may be biased toward their priorities and favorites without considering the overall regional balance and benefit. Such urbanization will cause imbalance in regional economic, social and ecological development and remains a big problem in China's urbanization process. Therefore, coordinated and collaborative development, which balances the individual municipalities' priorities and overall regional interests, should be implemented in the urbanization process through coordinating and integrating all related stakeholders in the region. Implementing the policy of intensive use of land resource on co-operation among various departments of local government is necessary for land use efficiency in the context of urbanization. Thus, balanced regional development is largely based on how these polices and strategies are organized and implemented.

According to the above analyses and discussions of landscape changes in BTC of the Beijing-Tianjin metropolitan area, landscape patterns were affected by urbanization. With the economic development into the new normal and the implementation of new urbanization 
strategies, the urban expansion in the Beijing-Tianjin metropolitan area should turn from occupying arable land on a large scale to utilize intensively land resources, effectively improve the economic growth, and enhance human welfare. Paying more attention to the different effects of urbanization in urban and rural areas is necessary to make plans in coordinated way following the national guidelines.

\section{Conclusions}

This study examined rapid-urbanization-induced landscape changes in Beijing-Tianjin corridor (BTC) in the context of the collaborative development in multiple municipalities. Multi-temporal land use maps derived from Landsat images were used to calculate landscape metrics and analyze their characteristics along the urban-rural gradients in BTC. The results demonstrated that: (1) landscape patterns in the area changed greatly from 2000 to 2015. (2) The overall changes could be characterized with a sprawl in construction land and a shrinkage in arable land. However, the intensity and scale of landscape changes varied along the urban-rural gradients. (3) Sampled plots in urbanized areas and rural areas showed evidently distinguishable landscape patterns. (4) The urban areas have more heterogeneous and fragmented landscapes than rural areas.

Peri-urban areas in general experienced a higher level of land diversification than rural areas. Rural residential land appeared to be more aggregated near Beijing and Tianjin. Beijing's influence on rural residential land and Tianjin's influence on other construction land might have reached beyond their immediate surrounding areas. Inspection of multi-temporal metrics indicated that landscape patterns have changed in response to urban expansion. This study not only presents a practical methodology for monitoring spatio-temporal changes of landscape patterns in large metropolitan areas, but also provides strategical insights into urban planning and rural revitalization in the new era around mega cities.

\section{References}

Aguilera F, Valenzuela L M, Botequilha-Leitão A, 2011. Landscape metrics in the analysis of urban land use patterns: A case study in a Spanish metropolitan area. Landscape and Urban Planning, 99(3/4): 226-238.

Antrop M, 2004. Landscape change and the urbanization process in Europe. Landscape and Urban Planning, 67(1): 9-26.

Bittner C, Sofer M, 2013. Land use changes in the rural-urban fringe: An Israeli case study. Land Use Policy, 33(1): 11-19.

Dewan A M, Yamaguchi Y, Ziaur Rahman M, 2012. Dynamics of land use/cover changes and the analysis of landscape fragmentation in Dhaka Metropolitan, Bangladesh. GeoJournal, 77(3): 315-330.

Dietzel C, Herold M, Jeffrey J H et al., 2005. Spatio-temporal dynamics in California's Central Valley: Empirical links to urban theory. International Journal of Geographical Information, 19(2): 175-195.

Fan C, Myint S, 2014. A comparison of spatial autocorrelation indices and landscape metrics in measuring urban landscape fragmentation. Landscape and Urban Planning, 121(1): 117-128.

Fernandes M R, Aguiar F C, Ferreira M T, 2011. Assessing riparian vegetation structure and the influence of land use using landscape metrics and geostatistical tools. Landscape and Urban Planning, 99(2): 166-177.

Gu C, Wei Y D, Cook I G, 2015. Planning Beijing: Socialist city, transitional city, and global city. Urban Geography, 36(6): 905-926.

Guo L, Di L, Li G et al., 2015. GIS-based detection of land use transformation in the Loess Plateau: A case study 
in Baota District, Shaanxi Province, China. Journal of Geographical Sciences, 25(12): 1467-1478.

Han F, Liu H, 2013. Transition matrix estimation in high dimensional time series. PMLR, 28(2): 172-180.

Kowea P, Pedzisaib E, Gumindogac W et al., 2015. An analysis of changes in the urban landscape composition and configuration in the Sancaktepe District of Istanbul Metropolitan City, Turkey using landscape metrics and satellite data. Geocarto International, 30(5): 506-519.

Lechner A M, Reinke K J, Wang Y et al., 2013. Interactions between land cover pattern and geospatial processing methods: Effects on landscape metrics and classification accuracy. Ecological Complex, 15(5): 71-82.

Li J, Deng J, Wang K et al., 2014. Spatiotemporal patterns of urbanization in a developed region of eastern coastal China. Sustainability, 6(7): 4042-4058.

Li J, Jia L, Liu Y et al., 2018. Measuring model of rural transformation development path in Fuping County of Beijing-Tianjin-Hebei region. Habitat International, 74(1): 48-56.

Li T, Long H, Liu Y et al., 2015. Multi-scale analysis of rural housing land transition under China's rapid urbanization: The case of Bohai Rim. Habitat International, 48(1): 227-238.

Li X, Zhou W, Ouyang Z et al., 2012. Spatial pattern of greenspace affects land surface temperature: Evidence from the heavily urbanized Beijing metropolitan area, China. Landscape Ecology, 27(6): 887-898.

Liu J, Kuang W, Zhang Z et al., 2014. Spatiotemporal characteristics, patterns, and causes of land-use changes in China since the late 1980s. Journal of Geographical Sciences, 24(2): 195-210.

Liu Y, Hu Z, Li Y, 2014. Process and cause of urban-rural development transformation in the Bohai Rim Region, China. Journal of Geographical Sciences, 24(6): 1147-1160.

Liu Y, Li Y, 2017. Revitalize the world's countryside. Nature, 548(7667): 275-277.

Liu Y, Lu S, Chen Y, 2013. Spatio-temporal change of urban-rural equalized development patterns in China and its driving factors. Journal of Rural Studies, 32(1): 320-330.

Liu Y, Luo T, Liu Z et al., 2015. A comparative analysis of urban and rural construction land use change and driving forces: Implications for urban-rural coordination development in Wuhan, Central China. Habitat International, 47(1): 113-125.

Liu Y, Yan B, Zhou Y, 2016. Urbanization, economic growth, and carbon dioxide emissions in China: A panel cointegration and causality analysis. Journal of Geographical Sciences, 26(2): 131-152.

Liu Y, Yang Y, Li Y et al., 2017. Conversion from rural settlements and arable land under rapid urbanization in Beijing during 1985-2010. Journal of Rural Studies, 51(1): 141-150.

Liu Y, Zhang Z, Zhou Y, 2018a. Efficiency of construction land allocation in China: An econometric analysis of panel data. Land Use Policy, 74(1): 261-272.

Liu Z, Liu Y, Li Y, 2018b. Anthropogenic contributions dominate trends of vegetation cover change over the farming-pastoral ecotone of northern China. Ecological Indicators, 95(1): 370-378.

Long H, 2014. Land consolidation: An indispensable way of spatial restructuring in rural China. Journal of Geographical Sciences, 24(2): 211-225.

Long H, Liu Y, 2016. Rural restructuring in China. Journal of Rural Studies, 47(1): 387-391.

Long H, Liu Y, Li X, 2010. Building new countryside in China: A geographical perspective. Land Use Policy, 27(2): 457-470.

Long H, Zou J, Liu Y, 2009. Differentiation of rural development driven by industrialization and urbanization in eastern coastal China. Habitat International, 33(4): 454-462.

$\mathrm{Lu}$ D, 2015. Function orientation and coordinating development of subregions within the Jing-Jin-Ji urban agglomeration. Progress in Geography, 34(2): 265-270. (in Chinese)

Lv Z, Dai F, Sun C, 2012. Evaluation of urban sprawl and urban landscape pattern in a rapidly developing region. Environmental Monitoring \& Assessment, 184(10): 6437-6448.

Martinuzzi S, Gould W A, Ramos González O M, 2007. Land development, land use, and urban sprawl in Puerto Rico integrating remote sensing and population census data. Landscape \& Urban Planning, 79(3): $288-297$.

McGarigal K, Tagil S, Cushman S A, 2009. Surface metrics: An alternative to patch metrics for the quantification of landscape structure. Landscape Ecology, 24(3): 433-450. 
Nagendra H, Munroe D K, Southworth J, 2004. From pattern to process: landscape fragmentation and the analysis of land use/land cover change. Agriculture, Ecosystems \& Environment, 101(2/3): 111-115.

Nilsson K, Sick Nielsen T, Aalbers C B E M et al., 2014. Strategies for sustainable urban development and urban-rural linkages. European Journal of Spatial Development, 27(3): 1-26.

Poelmans L, Van Rompaey A, 2009. Detecting and modelling spatial patterns of urban sprawl in highly fragmented areas: A case study in the Flanders-Brussels region. Landscape and Urban Planning, 93(1): 10-19.

Qian J, Peng Y, Luo C et al., 2016. Urban land expansion and sustainable land use policy in Shenzhen: A case study of China's rapid urbanization. Sustainability, 8(1): 1-16.

Roose A, Kull A, Gauk M et al., 2013. Land use policy shocks in the post-Communist urban fringe: A case study of Estonia. Land Use Policy, 30(1): 76-83.

Seto K C, Fragkias M, 2005. Quantifying spatiotemporal patterns of urban land-use change in four cities of China with time series landscape metrics. Landscape Ecology, 20(7): 871-888.

Shahtahmassebi A, Pan Y, Lin L et al., 2014. Implications of land use policy on impervious surface cover change in Cixi County, Zhejiang Province, China. Cities, 39(1): 21-36.

Shoyama K, Braimoh A K, 2011. Analyzing about sixty years of land-cover change and associated landscape fragmentation in Shiretoko Peninsula, Northern Japan. Landscape and Urban Planning, 101(1): 22-29.

Simwanda M, Murayama Y, 2018. Spatiotemporal patterns of urban land use change in the rapidly growing city of Lusaka, Zambia: Implications for sustainable urban development. Sustainable Cities \& Society, 39(1): 262-274.

Song W, Chen B, Zhang Y, 2013. Land use regionalization of rural settlements in China. Chinese Geographical Sciences, 23(4): 421-434.

Su C, Fu B, Lu Y et al., 2011. Land use change and anthropogenic driving forces: A case study in Yanhe River Basin. Chinese Geographical Sciences, 21(5): 587-599.

Sun Y, Zhao S, 2018. Spatiotemporal dynamics of urban expansion in 13 cities across the Jing-Jin-Ji Urban Agglomeration from 1978 to 2015. Ecological Indicators, 87(1): 302-313.

Taubenböck H, Wegmann M, Roth A et al., 2009. Urbanization in India: Spatiotemporal analysis using remote sensing data. Computers, Environment and Urban Systems, 33(3): 179-188.

Tian Q, Guo L, Zheng L, 2016. Urbanization and rural livelihoods: A case study from Jiangxi Province, China. Journal of Rural Studies, 47(Part B): 577-587.

Wang J, Wang X, 2015. New urbanization: A new vision of China's urban-rural development and planning. Frontiers of Architectural Research, 4(2): 166-168.

Wang Y, Liu Y, Li Y et al., 2016. The spatio-temporal patterns of urban-rural development transformation in China since 1990. Habitat International, 53(1): 178-187.

Wei Y D, 2015. Spatiality of regional inequality. Applied Geography, 61(1): 1-10.

Yu D, Wei Y D, 2008. Spatial data analysis of regional development in Greater Beijing, China, in a GIS environment. Papers in Regional Science, 87(1): 97-117.

Zhao P, 2010. Sustainable urban expansion and transportation in a growing megacity: Consequences of urban sprawl for mobility on the urban fringe of Beijing. Habitat International, 34(2): 236-243.

Zhao S, Zhou D, Zhu C et al., 2015. Spatial and temporal dimensions of urban expansion in China. Environmental Science \& Technology, 49(16): 9600-9609. 